\title{
O MOVIMENTO SOFTWARE LIVRE DO BRASIL: POLIIIICA, TRABALHO E HACKING ${ }^{*}$
}

\author{
Rafael Evangelista \\ Universidade Estadual de Campinas - Brasil
}

Resumo: A proposta deste trabalho é discutir, a partir de dados etnográficos, as características, contradições e transformações da comunidade software livre brasileira vividas nos últimos anos. Entendida como um movimento social, busca-se mostrar como ela inter-relaciona questões que envolvem política, linguagem, trabalho e identidade. O cenário etnográfico abordado mistura o online com o offline, ou seja, a pesquisa procurou entender o software livre tanto por meio da pesquisa de campo tradicional como pela observação de grupos online. O movimento software livre brasileiro se mostrou, comparado com seus equivalentes internacionais, como de grande eficácia: articulou-se com partidos e políticos tanto em nível local como nacional, mostrando-se influente a ponto de ver atendidas certas demandas; alguns de seus membros obtiveram cargos técnicos e administrativos; e foi possivelmente o grupo mais influente na constituição dos grupos que atualmente identificam-se sob o termo guarda-chuva "cultura digital". A pesquisa que dá base ao texto já resultou em tese de doutoramento e reúne dados coletados por dez anos de envolvimento com a comunidade software livre, incluindo interações e participação em eventos offline, sendo o mais importante deles o Fórum Internacional de Software Livre, realizado anualmente em Porto Alegre.

Palavras-chave: cibercultura, movimentos sociais, politica, software livre.

Abstract: This paper's goal is to discuss (using ethnographic data) the characteristics, contradictions and changes along time of the Brazilian free software community. The community is understood as a social movement and I seek to demonstrate how it interconnects politics, language, labor and identity. The fieldwork relies on both online and offline data. The research tried to comprehend the free and open source

* Trabalho apresentado na $28^{\mathrm{a}}$ Reunião Brasileira de Antropologia, realizada entre os dias 2 e 5 de julho de 2012, em São Paulo, Brasil.

Horizontes Antropológicos, Porto Alegre, ano 20, n. 41, p. 173-200, jan./jun. 2014 http://dx.doi.org/10.1590/S0104-71832014000100007 
phenomena using from traditional ethnographic work but also observing the group's behavior on online discussion groups and mailing lists. The Brazilian free and open software movement showed to be of great efficiency if compared with other international FLOSS (Free/Libre/Open Source Software) communities: it became influential on political parties both locally and nationally; some of its members became part of governments; and have contributted decisively on the build of the imagination on what is "digital culture". This paper is the result of a PhD research effort and relies on ten years involvement with the free software community including fieldwork with the Free Software International Forum (Fisl).

Keywords: cyberculture, free software, politics, social movement.

Desde meados da década de 1990, um grupo de pessoas vem atuando no Brasil no sentido de propor a adoção e contribuir para o uso do que se convencionou chamar de softwares livres. Esse grupo, nem sempre homogêneo em seus posicionamentos, intitula-se "movimento software livre" e reúne técnicos, desenvolvedores, ativistas, usuários, organizações, empresas, empresários, artistas e intelectuais. Este trabalho é uma tentativa de aproximação a esse grupo, uma escrita de caráter etnográfico no sentido de tentar entender o software livre - um movimento que é mundial - a partir de quase dez anos de anos de experiência de campo junto a militantes brasileiros.

Embora tenha nascido nos Estados Unidos, em meio à popularização do uso dos microcomputadores, o movimento software livre ganhou, no Brasil, especial relevância. Após menos de dez anos de atuação, teve destaque pelo seu número de integrantes; pelo tamanho de seus eventos (o Fórum Internacional de Software Livre, realizado anualmente em Porto Alegre, Rio Grande do Sul, está entre os dois maiores do mundo); e por sua influência junto a governos municipais, estaduais e federal. Na imprensa internacional, o Brasil já foi classificado, em matérias de publicações especializadas, como "o maior e melhor amigo do software livre" (Benson, 2005; Festa, 2001; Kingstone, 2005). O então ministro da Cultura, Gilberto Gil, se disse apoiador da "ética hacker" (Gilberto Gil..., 2006) e classificou a si mesmo como um "hacker", termo utilizado por integrantes do movimento para, entre outras adjetivações possíveis, qualificar seus membros mais importantes. No setor da cultura, as políticas e o fomento a grupos adotados na gestão de Gil são citados como inspiração por ativistas de todo o mundo. 
A proposta deste trabalho é considerar todo esse amplo grupo como igualmente relevante para o movimento, e não somente os setores mais técnicos. A literatura sobre o movimento software livre, que o pensa tanto em sua configuração global como brasileira, em grande parte tem escolhido como objeto de investigação as empresas ou os indivíduos envolvidos mais diretamente na produção e melhoria dos softwares (Apgaua, 2004; Coleman, 2004; Kelty, 2008; Sanchez, 2007; Weber, 2004; entre outros), muitas vezes referindo-se a eles como "hackers", para designar o grupo em seu caráter específico. ${ }^{1}$ Ao ampliar a lente, entendendo o software livre como um movimento social mais complexo, procuro atentar para relações que integram cultura, política, ideologia, trabalho e poder.

\section{Free e open, uma divisão histórica}

É impossível falar do software livre, enquanto movimento, sem falar de suas ambiguidades, contradições e divisões. Certamente, são elas que permitem que segmentos sociais diferentes, muitas vezes com interesses opostos - como ativistas antiglobalização e empresas - encontrem algum tipo de representação a partir da qual descreverão o adversário e os objetivos do movimento com diferentes matizes (Coleman, 2004). Tomo como divisão política primeira do software livre o que chamo de grupos free e open. Esses grupos, a partir de um mesmo conjunto de valores gerais, mobilizarão argumentos diferentes, seduzindo grupos distintos a participarem do movimento.

Surgido no início dos anos 1980, o movimento software livre passa a apresentar, a partir do final dos anos 1990, momento que irrompe para a atenção mundial, uma disputa bastante clara. Formalmente estabelecem-se dois grupos: o free, que afirma ter como luta fundamental a "liberdade" dos usuários de software e ter como horizonte imediato o uso exclusivo de softwares livres; e o open, que embora afirme buscar as mesmas "liberdades" que o free, o faz a partir de outras instituições e com diferentes estratégias de luta - por exemplo, colocando o modelo livre de licenciamento de software como uma alternativa a coexistir com o modelo proprietário e argumentando que, acima

1 Aqui, ao contrário, pretendo entender - e discutir - o termo "hacker" como categoria nativa utilizada como ferramenta de distinção de certos membros, notadamente os de mais prestígio.

Horizontes Antropológicos, Porto Alegre, ano 20, n. 41, p. 173-200, jan./jun. 2014 
de tudo, a abertura do código-fonte oferecida pelas licenças livres favorece o desenvolvimento de um software de melhor qualidade. Para o grupo free e para o grupo open existem instituições, organizações distintas, ${ }^{2}$ às quais indivíduos do movimento software livre podem mostrar-se ligados com graus variados de intensidade. Apenas alguns poucos são formalmente ligados a elas, vários colaboram com uma ou outra em campanhas específicas, sendo que a maioria manifesta apoio e concordância com elas, ou com o conjunto de ideias que representam, de maneira não direta. A fronteira entre os grupos é porosa e o comportamento da maioria dos indivíduos dificilmente é completamente de acordo com os preceitos de cada um dos grupos.

Essa distinção entre free e open vai se fundamentar operando no terreno da construção ideológica, ou seja, trata-se da disputa entre duas correntes políticas que, por meio das ideias que divulgam, procuram arregimentar aliados que, por sua vez, mobilizarão trabalho social em benefício do $\mathrm{m}$ vimento software livre como um todo, mas também mais especificamente em benefício de um dos grupos. Ao racionalizar, justificar, a prática de produção de softwares livres, cada um dos grupos vai apresentar um sentido, uma motivação geral, um propósito diferente (Wolf, 2001, p. 313). Ambos, contudo, o farão buscando elementos contidos em um ambiente cultural mais amplo e, assim, serão informados e sofrerão os efeitos das transformações pelas quais passa a sociedade capitalista contemporânea.

A disputa entre os grupos free e open em torno da construção daquela que será a ideologia do movimento nos permite discutir ainda como o movimento software livre origina e se estrutura em um determinado arranjo da produção para o desenvolvimento de seus softwares. O grupo open faz do elogio às virtudes práticas desse arranjo da produção o principal argumento para a defesa do software livre. ${ }^{3}$

Como dito, software livre nasce em meio a mudanças importantes do capitalismo, com um crescimento acelerado dos lucros das empresas de

\footnotetext{
2 A Free Software Foundation é a mais representativa do grupo free, enquanto a Open Source Initiative é a mais representativa do grupo open. Essas são organizações gerais de defesa do software livre, mas há diversas outras, que defendem pontos específicos, causas correlatas (como a inclusão digital com software livre) ou têm atuação regional, e que se alinham mais com o grupo free ou open.

3 O termo utilizado pelo grupo open para se referir ao software livre é open source. Utilizo, contudo, o termo software livre para me referir ao conjunto amplo dos softwares defendidos pelos grupos open e free que, fundamentalmente, é o mesmo.
}

Horizontes Antropológicos, Porto Alegre, ano 20, n. 41, p. 173-200, jan./jun. 2014 
tecnologia de informação e comunicação. E colabora para uma mudança no estilo de fazer negócios e de produzir software dessas empresas, cujo modelo principal, até então, era semelhante ao de uma empresa manufatureira: produzia-se e vendia-se software como se fosse um bem material. No software livre, embora também estejam envolvidos em seu processo de produção trabalhadores contratados diretamente pelas empresas, que vendem sua força no mercado - formando parte importante do trabalho utilizado para a produção de softwares livres - o trabalho tido como modelo e simbolicamente ostentado como o mais característico da produção livre é de tipo voluntário, realizado no tempo "de folga" do trabalhador e fora dos espaços típicos de trabalho capitalista (não acontece nem na fábrica nem nos escritórios das empresas). Progressivamente, os softwares produzidos por esse modelo, e a própria ideia de modelo distribuído de produção, tem ganhado espaço nas grandes empresas de tecnologia. ${ }^{4}$

Free e open apresentam versões ligeiramente diferentes para o surgimento do movimento software livre. A Free Software Foundation aponta o ano de 1983, com o lançamento do projeto GNU (acrônimo para a expressão em inglês "GNU não é Unix") por Richard Stallman, como marco inicial do movimento (Free software..., 2004). Já a Open Source Initiative descreve um percurso histórico mais longo, atribuindo o nascimento do movimento a uma cultura de compartilhamento de software existente desde a década de 1960, principalmente entre pesquisadores da Universidade de Berkeley, na Califórnia, envolvidos no desenvolvimento do sistema operacional Unix e do BSD (Berkeley Software Distribution). Steven Weber (2004) recupera essa história mostrando as tensões entre a companhia telefônica AT\&T, detentora inicial do código do Unix, laboratórios de pesquisa e pesquisadores universitários em torno dos direitos de uso e compartilhamento desses códigos.

Enquanto movimento social com princípios e objetivos constituídos, o triênio 1983-1984-1985 parece ser particularmente relevante. A cultura de compartilhamento de software que Weber localiza especialmente entre os pesquisadores da Califórnia não era algo exclusivo. Contrariado com

4 O conjunto de servidores que forma a plataforma Google utiliza versões modificadas do Linux e de outros softwares livres (Jelassi; Enders, 2005). Para o desenho de produtos, diversas empresas estão criando softwares em que os próprios consumidores colaboram na criação. A prática é conhecida como crowdsourcing e baseia-se na descentralização da produção do software livre (Kaufman, 2008).

Horizontes Antropológicos, Porto Alegre, ano 20, n. 41, p. 173-200, jan./jun. 2014 
a impossibilidade de examinar o código-fonte do programa controlador de uma impressora devido a novas regras de propriedade sobre softwares que começavam a se estabelecer, Richard Stallman lança o projeto GNU em 1983. O objetivo era construir um sistema operacional similar ao Unix, mas que obedecesse a uma licença em que os programadores poderiam fazer tudo com o software, menos torná-lo proprietário. Entre 1984 e 1985, Stallman evolui essa ideia e escreve o Manifesto GNU, documento que desenha os princípios do copyleft, ${ }^{5}$ que dará base para as regras descritas na GPL - a principal licença do software livre, publicada em 1989. O manifesto é um convite para que outros programadores se unam ao esforço da então recém-fundada Free Software Foundation (FSF) de produzir um sistema operacional livre. Em 1984, Stallman abandona seu emprego no Massachusetts Institute of Technology (MIT) para dedicar-se totalmente à causa do software livre. É nesse período que ele delineia o que chama de princípios éticos, as quatro liberdades que fundamentam o movimento: o software deve ser livre para ser modificado, executado, copiado e distribuído. O documento por excelência que marca a luta por essas liberdades é a GPL, a primeira licença redigida tendo em vista os objetivos do movimento. ${ }^{6}$

Outro ano importante é 1991, quando Linus Torvalds lança a primeira versão do kernel $^{7}$ Linux, que tornou completo o sistema livre projetado pela FSF, o GNU. Embora seja licenciado nos termos da GPL, o Linux significou, na prática, um forte impulso para uma nova corrente de poder dentro do movimento, que culminará com o ascensão do open source, enquanto ideia e grupo político, em 1998. Naquele ano, Eric Raymond (1998) publica o artigo "Goodbye, 'free software'; hello, 'open source"” e funda, com Bruce Perens,

\footnotetext{
Copyleft é um termo criado por Richard Stallman para se opor ao copyright. Segundo ele, a ideia veio de um colega que grafou: "Copyleft, all rights reversed", fazendo um trocadilho com o termo e com a frase "all rights reserved" que acompanha o copyright. O termo também é interpretado como uma alusão ao espectro da esquerda na política.

6 Kelty (2008) conta os problemas que Stallman teve ao tentar compartilhar seu programa EMACS com outros desenvolvedores e sua tentativa de construir em torno do programa uma comunidade/comuna (Stallman utilizava o termo commune, mas o termo community acabou por se tornar mais popular ao longo dos anos para se fazer referência a esses grupos de usuários e desenvolvedores), preservando-o de empresas que desejavam torná-lo um software proprietário. Segundo Kelty, essas dificuldades serviram de aprendizado para que Stallman desenvolvesse a licença livre GPL.

7 O kernel é uma parte central do sistema, responsável pela configuração e gerenciamento dos dispositivos (teclado, mouse, monitor, etc.).
}

Horizontes Antropológicos, Porto Alegre, ano 20, n. 41, p. 173-200, jan./jun. 2014 
a Open Source Initiative (OSI). Considero aqui a Free Software Foudation como a instituição mais representativa da visão do grupo free ${ }^{8} \mathrm{e}$ a Open Source Initiative como instituição que dará suporte inicial às ideias do grupo open.

Stallman continua, até hoje, tendo grande influência no movimento. No entanto, a partir de 1991 ele se vê obrigado a dividir o palco com uma então jovem estrela da Finlândia, Linus Torvalds. Carismático, empreendedor, e sabendo usar melhor a internet, ele conseguiu dar solução a um problema a que a FSF se dedicava há anos: construir um kernel licenciado sob uma licença livre para ser parte integrante de um sistema operacional livre. A FSF já tinha todo o resto da estrutura do sistema pronta, fruto de anos de esforços, e trabalhava no desenvolvimento de seu próprio kernel. Linus foi mais rápido e, usando a GPL como licença, adotou soluções tecnicamente mais eficientes, criando o Linux, parte essencial do sistema operacional.

O método de desenvolvimento adotado por Linus está delineado formalmente em A catedral e o bazar, livro escrito por Eric Raymond, em 1997. A obra é uma reflexão, elogio e uma descrição do que seria um modelo aberto de desenvolvimento, chamado "bazar". Trata-se, também, de uma alfinetada em Stallman e na FSF, acusados de adotar uma postura centralizadora na organização do trabalho coletivo do projeto GNU. A crítica de Raymond aparentemente é voltada ao modelo de desenvolvimento proprietário, mas também refere-se à FSF ao apontar que, até o trabalho de Torvalds, os códigos eram como se fossem "catedrais", monumentos sólidos construídos a partir de um grande planejamento central. Já o desenvolvimento adotado por Torvalds seria como um bazar, com uma dinâmica altamente descentralizada. Raymond aponta méritos em Torvalds não somente pela liderança no projeto Linux, mas por adotar um relacionamento com seus contribuidores no projeto diferente do até então adotado û`las empresas de software proprietário e pela própria Free Software Foundation. Diz Raymond (1997, p. 3):

De fato, eu penso que a engenhosidade do Linus e a maior parte do que desenvolveu não foram a construção do kernel do Linux em si, mas sim a sua invenção do modelo de desenvolvimento do Linux.

\footnotetext{
8 Essa ideia permanece válida até bastante recentemente. Porém, há indícios que o enfraquecimento do subgrupo free tenha sido tão acentuado que suas ideias estejam perdendo força até mesmo dentro de sua instituição fundadora, que permanece bastante atuante.
}

Horizontes Antropológicos, Porto Alegre, ano 20, n. 41, p. 173-200, jan./jun. 2014 
A virtude desse novo método de Torvalds estaria, principalmente, na publicação frequente e precoce das alterações feitas no código-fonte. Assim, desenvolvedores de todo o mundo teriam a possibilidade de ler as alterações no código, realizar testes em máquinas diferentes e enviar sugestões de modificações a Torvalds. A essa prática Raymond denominou bazar e aponta suas raízes na cultura universitária dos anos 1960 e 1970.

Mas há mais no que diz Raymond com relação ao modelo Linux do que o elogio da astúcia e da técnica - embora o sucesso desta seja inegável -, há uma disputa de poder sobre quem representa e o que significa o movimento. Stallman sempre foi uma figura politicamente muito atuante, não apenas no campo da informática. Mais velho, tendo vivido toda a experiência da luta pelos direitos civis nos EUA, Stallman carrega em sua fala críticas não muito ao gosto das empresas, em especial um conjunto de empresas da Califórnia que está tentando transformar o Linux em negócio. No site pessoal de Stallman, por exemplo, ao lado de artigos em favor do software livre encontram-se também ensaios políticos sobre temas como a invasão estadunidense ao Iraque e o muro de Israel na Palestina. Raymond, por sua vez, é um ardoroso defensor da liberalização do uso de armas, tema usualmente mais ligado às bandeiras da direita estadunidense (os conservadores). Já Torvalds, além de ser politicamente bastante moderado e pragmático, tem uma identidade maior com a então nova geração de programadores abaixo dos 40 anos, da qual Raymond faz parte. Essa geração, segundo Sam Willians em Free as in Freedom - livro que mistura notas biográficas de Stallman com a história do software livre - é mais energética e ambiciosa. Diz Williams (2002, p. 156, tradução minha):

Com Stallman representando o mais velho, mais experiente contingente de $h a-$ ckers ITS/Unix [ITS/Unix são sistema utilizados largamente por técnicos até a década de 1980. O GNU/Linux foi construído com uma arquitetura semelhante a desses sistemas] e Torvalds representando a safra mais jovem, mais energética de hackers Linux, o pareamento indicava uma demonstração de unidade simbólica que só poderia ser benéfica, em especial para hackers mais jovens (abaixo dos 40) e ambiciosos como Raymond. ${ }^{9}$

9 No original: "With Stallman representing the older, wiser contingent of ITS/Unix hackers and Torvalds representing the younger, more energetic crop of Linux hackers, the pairing indicated a symbolic show of unity that could only be beneficial, especially to ambitious younger (i.e., below 40 ) hackers such as Raymond."

Horizontes Antropológicos, Porto Alegre, ano 20, n. 41, p. 173-200, jan./jun. 2014 
Stallman representaria a velha geração, o discurso político dos anos 1970, sobrevivente à era Reagan nos anos 1980. Já Torvalds pôde representar os novos programadores, que ascenderam com a bolha da internet do final da década de 1990 e com o ápice do neoliberalismo, e que hoje aspiram por empregos da nova indústria de tecnologia, com imagem alternativa (mas não anticapitalista) das novas corporações de informação e comunicação.

Desde a popularização do trabalho de Torvalds, boa parte do tempo de Stallman tem sido gasta em pedidos para que todos se refiram ao sistema operacional, ao conjunto do software, como GNU/Linux e não apenas Linux. O projeto de Torvalds ganhou tanta repercussão que o sistema completo é mais conhecido como Linux. Stallman diz apenas querer que seu trabalho, e de toda FSF, seja reconhecido, já que, sem eles, não teria sido possível a existência do Linux. Dizer Linux ou GNU/Linux também tornou-se um marcador de maior afinidade com o grupo free ou com o grupo open.

O discurso politizado e o radicalismo de Stallman (que defende que todo software deve ser livre e que o software proprietário é "antiético") não são atrativos para a nova geração de programadores e o são ainda mais indigestos para os empresários, mesmo os ditos modernos novos empreendedores da internet. Raymond teve um papel decisivo na criação da alternativa mais ao gosto do paladar corporativo. Como dito em A catedral e o bazar, ele descreveu um processo de produção inovador e descentralizado, em que as alterações no software são rapidamente entregues à comunidade. Esta, testando e avaliando o produto, estabeleceria uma espécie de seleção natural em que as melhorias sobrevivem e as soluções falhas são logo identificadas. ${ }^{10}$ Esse argumento de Raymond seduziu executivos da Netscape, dona de um navegador de internet que havia sido destruído pela ofensiva agressiva - e anticompetitiva, segundo tribunais dos EUA - da Microsoft com seu Internet Explorer. Em 1998, Raymond foi a peça-chave no processo de convencimento dos executivos da Netscape para que usassem uma licença livre para o navegador - então comercialmente morto - de modo que a comunidade continuasse seu desenvolvimento. $\mathrm{O}$ código do Netscape, tornado livre, deu origem ao Mozilla Firefox, que pouco mais de cinco anos depois passou a rivalizar novamente

\footnotetext{
10 "Analyzing the success of the Torvalds approach, Raymond issued a quick analysis: using the Internet as his 'petri dish' and the harsh scrutiny of the hacker community as a form of natural selection, Torvalds had created an evolutionary model free of central planning." (Williams, 2002, cap. 11).
} 
com o Internet Explorer da Microsoft. O prestígio adquirido por Raymond (tanto pela liberação do código da Netscape como pelo livro $A$ catedral $e o$ bazar), somado ao do carismático Torvalds, foram essenciais para que o grupo open pudesse se estabelecer.

A confusão entre livre e grátis, que na língua inglesa têm o sentido referenciado pela mesma palavra, free, foi a justificativa formal para que surgisse o termo open source. Frequentemente, Stallman procura, chegando a ser insistente, deixar claro que o free de free software não significa grátis, mas livre. Não há diferenças substanciais entre o que os termos free software e open source pretendem definir. Ambos estabelecem praticamente os mesmos parâmetros que uma licença de software deve conter para ser considerada livre e aberta. Ambos estabelecem, na prática, que o software deve respeitar as liberdades básicas que a FSF enunciou (executar, copiar, distribuir, estudar, mudar e melhorar o software). Mas os defensores do termo open source afirmam que o termo fez com que os empresários percebessem que o software livre também pode ser comercializado. Teriam sido mudanças "pragmáticas" e não "ideológicas".

\section{0 surgimento do Fisl: entre movimentos sociais e partidos de esquerda}

O Fórum Internacional de Software Livre (Fisl) é um evento que reúne, desde o ano 2000, grande parte do que se convencionou chamar de "comunidade software livre brasileira". Dessa comunidade faz parte uma gama complexa de indivíduos que qualificam a si mesmos principalmente de acordo com suas ocupações: desenvolvedores (que desenvolvem, modificam o softwares), programadores (que oferecem instruções para que os softwares funcionem), usuários, funcionários de governo, políticos, estudantes de computação, jornalistas, ativistas sociais, empresários, etc. Ao longo do tempo, essa comunidade cresceu, superando principalmente o limite do conhecimento técnico, envolvendo cada vez mais usuários de nível intermediário e simpatizantes de algumas das ideias gerais do software livre. Concomitantemente, o movimento software livre também cresceu internamente, conquistando progressivamente a simpatia e/ou interesse de profissionais e estudiosos da computação. Um olhar sobre o Fisl é também um olhar consistente sobre o movimento brasileiro.

Ao longo dos anos, o evento consolidou uma determinada estrutura organizativa que mistura feira de negócios e exposições, congresso científico e fórum político de debates. Esse formato híbrido pode ser inicialmente explicado 
pela história do Fisl. Surgido entre funcionários públicos de tecnologia, ligados a sindicatos e movimentos de esquerda, o evento buscou sua base de público entre estudantes e profissionais da computação. Esses profissionais e estudantes convivem, geralmente, com empresas de todos os tamanhos, de onde retiram seu sustento (como empregados ou patrões) e que costumam estar presentes em eventos da área. Some-se a isso o fato de o Fisl ocorrer em Porto Alegre, cidade que no início do século XXI viveu uma grande efervescência política como local de realização das primeiras edições do Fórum Social Mundial (entre 2001 e 2003). O que em um primeiro momento pode parecer contraditório (a conjunção entre setores em certa medida anticapitalistas e o espaço para as empresas) faz sentido dado o perfil dos setores mobilizados, refletindo conjuntamente o ambiente de eventos para estudantes, militantes políticos e empresários/trabalhadores. A persistência desse formato híbrido ao longo dos anos, como veremos, pode ser entendida como resultado da continuidade de certos debates e divisões políticas, assim como pelo atendimento de demandas apresentadas pelos diversos públicos-alvo e de financiamento da estrutura material.

Tendo como pergunta principal de pesquisa a influência do movimento software livre no governo federal, principalmente após a posse de Luiz Inácio Lula da Silva, Aaron Shaw (2011) oferece uma visão interessante sobre alguns dos personagens que construíram as fundações do movimento software livre brasileiro e que participaram ativamente dos primeiros anos da organização do Fisl. Segundo Shaw, parte deles compartilhava uma história nos movimentos de esquerda do país e, quando o governo Lula atingiu o poder, levaram à frente um discurso radical, buscando politizar o papel do Estado desenvolvimentista em uma economia do conhecimento. Os membros do movimento software livre brasileiro possuiriam características únicas, se comparados a seus pares internacionais. A principal delas seria a orientação política, uma mistura de neomarxismo com socialismo.

Um dos indivíduos entrevistados por Shaw e que contribuem para que ele forme essa percepção sobre o movimento brasileiro é Mario Teza, bastante ativo na organização do Fisl até hoje. Teza é nascido em 1964, em Porto Alegre, e aponta o início de sua identificação com a esquerda como tendo acontecido no final dos anos 1970, quando das greves que levaram à formação do Partido dos Trabalhadores. Logo quando inicia em seu primeiro emprego, na estatal Serviço Federal de Processamento de Dados (Serpro) da capital gaúcha, 
Teza entra para o sindicato e torna-se presidente da seção local da Federação Nacional dos Empregados em Empresas e Órgãos Públicos e Privados de Processamento de Dados, Serviços de Informática e Similares (Fenadados). Shaw prossegue escrevendo a história da relação de Teza com o software livre, relatando em particular a sua articulação com Marcelo Branco, um amigo de Porto Alegre e então diretor da estatal Companhia de Processamento de Dados do Rio Grande do Sul (Procergs), que resultou na criação do Fisl, além de outros indivíduos com o mesmo perfil político e história de vida bastante semelhante: formação técnica em informática, mesma faixa etária, funcionários de empresas públicas e alguma relação com movimentos de esquerda e o PT. Nesse sentido, um depoimento de Teza ${ }^{11}$ colhido por Shaw (2011, p. 259) é emblemático do significado que parte dos organizadores históricos do Fisl dão ao software livre, mostrando que, pelo menos para alguns eles, o software livre significava uma possível "transcendência do capitalismo" e um meio para superar as limitações naturais das lutas sindicais:

By 1989, the labor movement was in crisis - it's still in crisis! But let's put it this way, for some people, we weren't satisfied with the labor movement and beyond that with the democratization - the unions also entered into a system - a status quo, let's say. It didn't subvert the social order after the creation of democracy, and for many of the activists at that time this was not enough. We wanted to do more. And for many of us, software livre has enabled us to do more. We are able to take direct action, break paradigms. The labor movement is incapable of this - it raises salaries, but it's a whole corporativist thing, its still very out of date. [The union] is a middle stage between the medieval guilds, the industrial revolution, and some other little bit of something modern - so-called modern as well. In reality, it's very dated and it doesn't overcome capitalism. In as much as software livre, without perceiving it, begins to transcend, at least challe ge capitalism, the ownership society, and intellectual property.

A partir de 1999, quando o PT chega ao governo do estado, Mario Teza, Marcelo Branco e Marcos Mazoni - então presidente da Procergs, Branco torna-se seu vice-presidente em 2000 -, fortificam ligações entre o PT, sindicatos de Porto Alegre, empresas estatais, movimentos sociais e setores interessados

11 Essa declaração de Teza foi colhida em 2005 e confirmam declarações com o mesmo tom colhidas por mim em anos anteriores.

Horizontes Antropológicos, Porto Alegre, ano 20, n. 41, p. 173-200, jan./jun. 2014 
em informática, a partir de certas ideias do software livre. Em julho de 1999, Branco, Teza e o técnico da Procergs, Ronaldo Lages, organizam o primeiro encontro visando discutir o assunto software livre no auditório da empresa municipal. Fazem-se presentes por volta de 40 pessoas e o grupo passa a se chamar Projeto Software Livre - Rio Grande do Sul, denominação que será, nos anos seguintes, copiada por organizações de defesa do software livre no Brasil todo.

Esse arranjo inicial contribuiu para dar ao software livre de Porto Alegre um perfil específico, ligado à esquerda. Já nessa época, os militantes porto-alegrenses procuram claramente se aproximar do grupo free, vendo nesse grupo, cujo representante mais saliente é Richard Stallman, maior afinidade de ideias. Ao que parece, essa aproximação com o free não era acompanhada com a mesma intensidade por outros grupos do resto do país.

Uma das iniciativas importantes no Brasil à época era a Revista do Linux, publicação editada pela empresa curitibana Conectiva, que comercializava, desde 1997 (Stulzer, 2004), a primeira distribuição brasileira de software livre. Shaw cita a participação de Teza em entrevista concedida pelo então governador do Rio Grande do Sul, Olívio Dutra, para o quinto número da Revista do Linux, datada de maio de 2000 (Governador..., 2000). Nessa entrevista, é mencionado o planejamento para o que se tornaria a primeira edição do Fisl, onde Dutra foi recebido efusivamente pelo público. Na conversa de Dutra com a Revista do Linux, publicação patrocinada por uma empresa e não partidária de um posicionamento radical, já se percebe uma divergência sobre como Olívio e a revista chamam o sistema operacional livre: Olívio fala em GNU/ Linux, enquanto a revista, nas perguntas, refere-se ao sistema como Linux, o que serve como marcador da distinção entre os grupos free e open. Em seu site pessoal, Teza mantém a transcrição de alguns depoimentos que deu relatando a história dos Fisl. Em um deles, ao comentar a participação de um profissional de Campinas no primeiro fórum, ele toca explicitamente na questão do nome a usar para o sistema operacional, deixando claro como isso envolve um certo posicionamento. É a transcrição literal de uma fala, sendo mantidas as retificações que o sujeito faz ao perceber que disse algo impróprio.

Segundo: quem nos ajudou muito, por incrível que pareça, morava em Campinas na época, o Eduardo Maçan. Então, como a gente debatia pela internet, ele tinha escrito um texto na Unicamp chamado... na época, ah! ele também chamava de 
gnu Linux de Linux, não chamava de gnu. O texto era "Linux na escola, no trabalho e em casa". [...]. Bom, aí quando a gente fez o debate nesse evento a gente discutiu o seguinte: Nos 4 anos de governo o que podemos fazer. Resolvemos fazer um planejamento de como faríamos este projeto numa linha de tempo. Em julho, o que nós discutimos para vocês entenderem. O Linux, o Gnu Linux [corrige-se] explodiu no mundo, ele surgiu em 1991, deu um primeiro pique em 1992 e realmente a explosão foi provavelmente em 1994, fora do Brasil. (Teza, 2004).

$\mathrm{Na}$ entrevista para a Revista do Linux, Dutra, além de insistentemente repetir o nome GNU/Linux a toda menção a Linux feita pelo repórter, dá indícios de como a ligação de seu governo com o software livre advém de uma ideia de que, por meio dele, é possível enfrentar questões que vão além à da liberdade dos usuários de software ou da qualidade do software produzido, como a inserção do país no mercado mundial de tecnologia, livrar-se da dependência de países estrangeiros e o acesso igualitário à tecnologia e às riquezas dela advindas.

Revista do Linux - Como foi que o senhor se envolveu com a questão do Linux? Qual a importância do projeto software livre para o Rio Grande do Sul?

Olívio Dutra - O meu envolvimento começou quando era deputado federal e atuava na Comissão de Ciência e Tecnologia da CUT. Tínhamos a preocupação de que a evolução científica e tecnológica proporcionasse melhorias na qualidade de vida para o conjunto da humanidade, em especial os excluídos, e não que servisse como mais um instrumento e acumulação de riquezas das elites.

$\mathrm{RdL}-[\ldots]$...muitos países tiveram seus caixas dizimados por déficits monstruosos e o Brasil não foge à regra. Diante do empobrecimento dos Estados, como na América Latina, o Linux passou a ser uma alternativa possível de informatização do Estado. O senhor diria que o Linux é mera solução de emergência ou um solucionador de dependências de terceiros? Uma alternativa para a falta de recursos ou um caminho de independência tecnológica?

Dutra - O GNU/Linux é um dos sistemas que representa informatização de qualidade para o Estado, e não se deve confundir a implementação desse produto nas empresas públicas como uma solução temporal, advinda de uma crise financeira. Sabemos que a necessidade é a mãe da criatividade, mas esse software aberto tem uma história recheada de bons resultados, além do que os programas abertos, livres de fato, proporcionam acesso a métodos de uma elaboração tecnológica muito rica em experiência, possibilitando utilizarmos todo esse conhecimento a serviço do Estado e do cidadão, livrando-nos enfim da dependência tecnológica. 
$\mathrm{RdL}-[\ldots] \mathrm{O}$ que muitos estranham é que até políticos como o senhor tenham se voltado para o assunto, e este é um fenômeno mundial, e que deixa a muitos perplexos. Porque o Linux hoje é assunto de Estado?

Dutra - Nosso governo tem uma identidade muito grande com esse tipo de projeto, [...] pelo GNU/Linux. Espero que muito em breve possamos encontrar soluções que viabilizem o acesso do cidadão aos microcomputadores também de forma gratuita, para que assim possamos ter uma sociedade em que seus participantes possam utilizar a tecnologia da informação em condições igualitárias. RdL - Como o senhor vê este movimento mundial, de cunho solidário, como o Open Source (código aberto)? Acredita que ele trará quais benefícios à sociedade?

Dutra - Os benefícios são inúmeros, mas gosto sempre de citar que para nós o mais importante é podermos ter no Brasil o retorno à produção de software, mantendo no país a inteligência e o controle sobre a tecnologia da informação. Podemos, finalmente, ter um sistema operacional que respeite as realidades regionais, operando com base nas idéias das pessoas que com ele trabalham, permitindo que cada comunidade possa se manter protagonista da sua própria história na evolução e acumulação do conhecimento científico e tecnológico. (Governador..., 2000).

A fala de Dutra deixa clara a ligação com o grupo free, ao insistir no termo GNU/Linux e ao apontar que os "programas abertos" são também "livres, de fato". Mas, além disso, há outras razões para a adoção dos softwares livres, como obstaculizar a "agregação de riqueza das elites", o fim da dependência tecnológica por parte do Estado, um acesso igualitário à tecnologia (dada a gratuidade do software) e o desenvolvimento de soluções mais adequadas à realidade regional (devido à possibilidade de modificações no código). Tratase de um conjunto original de argumentos, com influência do grupo free, mas também fruto de uma interpretação específica feita por movimentos sociais de esquerda, funcionários públicos e políticos que lidam com os problemas de países pobres.

Um exame das páginas publicadas na internet pelos organizadores do Fisl, ${ }^{12}$ confirma que a ideia do software livre como fator de mudança social já estava presente nesses primeiros anos do evento. Tenta-se combinar o mundo dos negócios com objetivos de transformação da estrutura da economia. Uma

12 Páginas que já não estão mais disponíveis regularmente, mas podem ser acessadas via serviços de armazenamento histórico da internet.

Horizontes Antropológicos, Porto Alegre, ano 20, n. 41, p. 173-200, jan./jun. 2014 
das preocupações dos organizadores era impulsionar os negócios das empresas de software livre, vistas como portadoras, em si, de um modelo econômico alternativo. Uma das seções do antigo site do Projeto Software Livre-RS tinha o título "Negócios livres". Nela, era possível encontrar o contato de empresas que trabalhassem com software livre em todo o país.

A importância de se estimular os negócios com as empresas de software livre é uma preocupação que persiste nas diversas edições do Fisl, estando ligada tanto à ideia de que isso levaria mais pessoas a "viverem de software livre" - "libertando-se" do "mundo do software proprietário" como à noção de que não é saudável ao "ecossistema do software livre" estar excessivamente ligado a iniciativas estatais. Desde os primeiros anos, nota-se a importância da estrutura estatal para a promoção das ideias do software livre, exemplificada pela clara interconexão entre o Projeto Software Livre-RS, organizador do Fisl, com o governo do estado do Rio Grande do Sul. As páginas, tanto do Fisl em suas primeiras edições, como do PSL-RS, funcionava em um domínio "rs.gov.br", ou seja, estava endereçada em um registro que pertence exclusivamente à administração estadual. Essa forte influência do governo estadual e municipal no evento foi substituída, mais tarde, quando da saída do PT do governo gaúcho e porto-alegrense, em forte influência do governo federal, a partir do governo Lula. Após 2003, o governo federal passou a contribuir mais consistentemente com o evento, oferecendo os patrocínios básicos que garantiram a sua realização em condições mínimas. Além disso, funcionários públicos, ligados neste segundo momento ao governo federal, continuaram colaborando com a organização. Contudo, não se trata necessariamente dos mesmos indivíduos, e estes estão menos ligados à estrutura interna de organização do Fisl (até por não estarem no Rio Grande do Sul) do que os colaboradores iniciais. Em 2003, a organização do Fisl tornou-se autônoma do PSL-RS, fundando uma ONG regularmente formalizada (a ASL.org) para gerir a organização do evento. Ao mesmo tempo, cresceu e diversificou-se o patrocínio oferecido pelas empresas privadas.

\section{Hackers, políticos e o público}

Para melhor descrever o público do evento, vou dividi-lo em quatro categorias. Essa não é uma divisão nativa - embora use em parte seus termos - nem tampouco implica em posicionar rigidamente os indivíduos nessas 
categorias. O objetivo é apenas oferecer um referencial sobre a origem e a motivação dos presentes. Essa descrição é histórica, mas também se verifica mais recentemente. $\mathrm{O}$ que tem mudado ao longo dos anos é o tamanho dos grupos e os indivíduos que a eles pertencem.

Burocratas: são os funcionários dos governos (municipal, estadual ou federal) ou de empresas públicas. Profissionalmente, realizam funções técnicas e/ou administrativas. Apenas uma pequena parte está envolvida diretamente no desenvolvimento de software. Em sua maioria são gerentes ou administradores de sistemas. Parte está envolvida com programas de inclusão digital. Normalmente estão no evento com todas as despesas pagas pelos seus empregadores, o que implica ficarem parte do tempo no estande de quem os emprega. Estão presentes mais nas sessões que discutem políticas de adoção de software livre em âmbito governamental e nos debates sobre a filosofia do software livre, embora não rejeitem as sessões técnicas. Quando necessário, usam terno ou roupa social, mas preferem vestir jeans e camiseta. Têm entre 25 e 50 anos.

Empresários: são donos ou funcionários de pequenas e médias empresas. Frequentam quase que exclusivamente as sessões técnicas, embora também tenham interesse em mesas que debatam políticas governamentais - onde buscam espaço para futuras prestações de serviço ou apresentam aos burocratas demandas de suas empresas. Têm bastante conhecimento técnico e estão no evento ou com recursos próprios ou de seus patrões. Usam terno ou roupa social. Têm entre 20 e 45 anos.

Ativistas: em geral têm pouco conhecimento técnico e, se o têm, são autodidatas. Parte tem formação técnica de nível médio e universitária em ciências humanas. Estão ligados a projetos de inclusão digital ou que envolvam arte (música, artes gráficas) em software livre. Usam bermuda e camiseta, também com motivos políticos. Frequentam as sessões que discutem a filosofia do software livre, novas regras de propriedade intelectual, inclusão digital e política de governo. Estão no evento com parcos recursos próprios, hospedados na casa de amigos e tendo viajado de ônibus. Parte tem ou já teve envolvimento com o movimento estudantil. Têm entre 18 e 30 anos.

Nerds: são, em geral, estudantes de computação. Frequentam principalmente as sessões técnicas. Aceitam as mesas sobre a filosofia do movimento, embora tenham uma visão bastante estrita sobre o tema. Vestem bermuda e camiseta, em geral com referência a personagens da cultura pop, piadas 
envolvendo conhecimento técnico ou projetos de software livre. Estão no evento com recursos próprios, e muitos vêm em caravanas de diferentes estados. Viajam e andam pelo Fisl em grupo. Estão interessados em aprender sobre tecnologia e em contatos profissionais. Têm entre 18 e 25 anos.

Essas quatro categorias, grosso modo, podem ser posicionadas em relação aos grupos free e open. Não significam correspondência direta verificável necessariamente em casos individuais, mas permitem entender melhor a divisão geral. Nerds e empresários costumam manifestar maior rejeição à presença de políticos e partidos no Fisl e não fazem grande esforço de ligar o software livre a outras lutas sociais. Ao contrário, os nerds frequentemente manifestam sua rejeição aos políticos, enquanto os empresários, embora tenham contato profissional com os políticos, procuram se manifestar como apartidários. Já os ativistas e os burocratas ou envolvem-se diretamente em outras lutas sociais ou não manifestam rejeição à interconexão delas com o software livre. Ambos têm também rejeição mais fraca à presença de políticos no evento.

Muitas vezes essa divisão burocratas/ativistas versus nerds/empresários aparecerá mascarada na subdivisão entre um público mais ou menos técnico, embora esse conhecimento mais avançado não seja um fato verificável. Pessoas com maior ou menor conhecimento técnico se espalham por todas as categorias e, além disso, o que parece existir mais concretamente é a preferência por determinados softwares ou linguagens de computador de acordo com os grupos. ${ }^{13}$

Dentro da própria estrutura organizadora do evento essa divisão é operada na classificação informal dos membros entre "hackers" e "políticos". De acordo com um informante, nessa divisão a qualificação de maior prestígio é "hacker", assim sendo chamados aqueles que, para o grupo, teriam conhecimentos mais técnicos. Porém, o que se verifica é que, mais do que conhecimento, é necessário um determinado posicionamento público e político para se merecer esse adjetivo de prestígio na estrutura da organização. Os "hackers" têm uma postura pública austera, até mesmo reservada, e, quando participam de um debate público - que quase sempre acontece por meio de e-mails em de

\footnotetext{
13 A linguagem Java, por exemplo, criada pela empresa Sun Microsystems, é bastante usada pelos nerds, além de ser a especialidade do representante da OSI no Brasil. Já o Twiki, software para construção de páginas web colaborativas, é largamente utilizado por membros do governo federal e por militantes do Projeto Software Livre Bahia, bastante identificado com outras causas político-sociais.
}

Horizontes Antropológicos, Porto Alegre, ano 20, n. 41, p. 173-200, jan./jun. 2014 
listas de discussão - esse debate costuma envolver a discussão de características técnicas de determinados softwares. O trabalho profissional do "hacker" (de onde retira seu sustento) quase nunca envolve diretamente governos e sua relação com ocupantes de cargos oficiais (deputados, vereadores, etc.) é distante. Já os "políticû1" da organização do Fisl são os que conversam e convidam as autoridades presentes no evento. Articulam o apoio financeiro e ocupam mais fortemente o papel de porta-vozes do Fisl e do próprio movimento. ${ }^{14}$ Por isso, os "políticos" são constantemente criticados, em especial pelos nerds - essas categorias são de uso geral, não restringem à organização do Fisl -, que apontam uma frequente contradição entre falar e fazer. Os "políticos" são acusados de falarem muito mas produzirem pouco, pois nunca estão envolvidos no "codar", escrever software e participar de grupos de desenvolvimento de programas. O "hacker" é uma categoria hierarquicamente mais elevada que o "político", que é visto sempre com maior desconfiança (por eventualmente querer "se aproveitar do software livre para outras causas"). Os "políticos" efetivamente trabalham muito mais na organização (conseguindo apoios, negociando com o movimento, conversando com a imprensa), mas os "hackers" são figuras mais respeitadas pela comunidade. Produzirûcódigo e ter conhecimento de programação são fatores muito importantes para se obter prestígio dentro do movimento de uma maneira geral. Contudo, não é possível fazer uma relação automática e progressiva (mais unidades de conhecimento não significam mais unidade de prestígio), trata-se de algo também mediado por uma atitude pública de distanciamento ou de relação fria com a política partidária tradicional.

Para o movimento software livre, a categoria "hacker" é algo essencial e congrega qualidades como criatividade, curiosidade, extrair prazer no trabalho e conhecimento técnico. É a distinção máxima que alguém pode receber dentro de um movimento que se considera "de hackers". Ser hacker é parte da identidade do movimento software livre, é algo que se refere não somente a pessoas mas a uma atitude com relação à vida e ao mundo. Fora da estrutura

\footnotetext{
${ }^{14}$ Murillo (2009) utiliza os termos "téc" e "ativistas" como referência a "hackers" e "políticos" do modo como trato aqui. Encontrei o uso desses termos em conversas com membros da organização do Fisl, porém, o "téc" estaria em um nível hierarquicamente inferior ao "hacker". O "téc" seria alguém mais jovem, muitas vezes - mas não necessariamente - com menor conhecimento técnico e mais ativo nos trabalhos gerais da organização do evento. "Ativistas" parece-me ser uma versão mais atenuada de "políticos”, porém não encontrei seu uso em específico.
}

Horizontes Antropológicos, Porto Alegre, ano 20, n. 41, p. 173-200, jan./jun. 2014 
contrastiva da organização, no software livre brasileiro de uma maneira geral, os ditos "políticos" do Fisl podem ser vistos e se declararem "hackers" - embora, ao se autoidentificarem, sejam recebidos internamente com certo ceticismo e ironia. Mas na estrutura da organização e do movimento eles são vistos como "políticos".

\section{Conclusão: unidade, divisão e mudança}

A distinção entre os grupos free e open oferece a base para que possamos entender os enfrentamentos, alianças e tomada de posições que acontecem no Fisl. Os símbolos vestidos e utilizados pelos participantes, por exemplo, originam-se em grande parte de grupos internacionais, que podem ser posicionados a partir dessa divisão.

No entanto, percebe-se que o discurso, em especial do grupo free, ganhou coloração própria quando reinterpretado por militantes brasileiros. A ideia de cooperação, colaboração, solidariedade e construção de um conjunto de softwares que fosse uma alternativa para o enrijecimento das regras de propriedade intelectual ganhou outra força ao aportar em um país subdesenvolvido de industrialização parcial. Técnicos, muitos ligados ao serviço público, e com passado ligado aos movimentos de esquerda, entenderam o movimento software livre também como uma resposta ao domínio das grandes empresas de informática e ao saque de riquezas promovido pelos países desenvolvidos. No horizonte, enxergou-se o software livre até como fator de transformação e superação da economia capitalista.

Foi assim que políticos de alguma forma identificados com a ideia de resistência à dominação e exploração externa incorporaram o software livre em seu repertório de propostas, somando-o a planos de independência nacional. Setores discordantes sobre essa interpretação da origem do subdesenvolvimento brasileiro ou descartaram o software livre como algo viável, ou mobilizaram argumentos típicos do grupo open, apontando sua melhor qualidade técnica como derivada do processo aberto de produção.

O movimento software livre, em especial o grupo free, requer de seus membros uma certa pureza, uma adequação entre defender o software livre com argumentos teóricos e extirpar da vida cotidiana o software proprietário. O palestrante do Fisl que utiliza software proprietário em sua apresentação é logo desacreditado pelo público. O membro do movimento que usa o sistema 
operacional Windows durante o evento - ou mesmo apenas o mantém instalado, em um setor separado, no disco de seu computador - é censurado pelos companheiros. Se a organização do evento utiliza um arquivo de vídeo em formato proprietário acaba sendo objeto de crítica pelo público. Os participantes procuram até mesmo retirar o adesivo do sistema Microsoft Windows que vem colado na maioria dos notebooks, substituindo-o por diversos adesivos alusivos ao software livre. É por possuir um conjunto até certo ponto estrito de regras de comportamento que podemos ouvir, nos corredores do Fisl, frases como "esse aí traiu/não traiu o movimento". Esse conjunto de restrições e recomendações funcionam de modo a, por um lado, estabelecer as divisões entre aqueles que pertencem - e dialogam com essas normas - ao movimento e aqueles que não pertencem. Ao mesmo tempo, o modo como são interpretadas - se são tidas como "exageradas" ou pertinentes - indica posicionamentos em relação às diversas subdivisões existentes.

Na cerimônia de encerramento do Fisl de 2009 pude acompanhar um episódio emblemático desse jogo de censura à associação com certas empresas, em que estas são associadas simbolicamente a determinadas práticas e posturas políticas. $\mathrm{O}$ anúncio da presença da Rede Globo no evento causou forte reação negativa no público. A empresa de comunicação, por seu histórico, mas também por sua posição dominadora no setor de comunicações, é associada ao gigante da indústria da informática e empresa inimiga do movimento, a Microsoft. Porém, não é isso que acontece, num processo que vem se acentuando nos últimos anos, com outras empresas, ascendentes e com uma imagem inovadora, como o Google e, então, a finlandesa Nokia (que atualmente vive declínio e tem se afastado do software livre). Esta, aliada do movimento em causas como a do padrão livre de arquivos ODF, é recebida com naturalidade, sendo sua presença até mesmo um sinal de que o evento não é anticapitalista. Não apenas as pessoas são interpretadas por sua relação favorável ou contrária ao software livre, mas também as companhias, lidas como sujeitos que escolhem entre o bem e o mal (aqui cabe lembrar o slogan "Don't be evil" do Google).${ }^{15}$ Com um histórico associado ao regime autoritário, distante de práticas de democratização da informação e de transparência, a Rede Globo é

\footnotetext{
15 A frase "Don't be evil" é citada frequentemente, em listas de discussão, como slogan corporativo do Google quando as atitudes da empresa estão em questão. A frase consta no prefácio do código de conduta da empresa, que pode ser acessado em: http://investor.google.com/corporate/code-of-conduct.html.
}

Horizontes Antropológicos, Porto Alegre, ano 20, n. 41, p. 173-200, jan./jun. 2014 
vista como oposta aos ideais do software livre, importando pouco o quanto ela de fato usa de código livre e com ele contribui. Ao mesmo tempo, um evento visto por muitos como radical, como o Fórum Social Mundial, é anunciado no mesmo palco, na mesma cerimônia, separado apenas por alguns minutos.

Embora seja inequívoca a existência de dois grupos no movimento software livre, há unidade parcial de ideias entre eles. Os membros do movimento, sejam eles do grupo open ou free, compartilham da ideia de progresso técnico da humanidade e tem, em geral, visões otimistas sobre o impacto da tecnologia na sociedade. No máximo, o que há são restrições ao que seria como o tipo errado de tecnologia, fechadas. Porém, as tecnologias tidas como livres, como o software livre e a internet, seriam democratizadoras e promotoras de uma evolução qualitativa da humanidade e do ambiente social.

O Fisl, integrando progressivamente free e open, e apresentando uma alternativa tecnológica cada vez mais pertencente ao capitalismo, tem sua unidade também alicerçada nessa síntese, na ideia de que é preciso haver foco no desenvolvimento tecnológico, acelerando-o.

Os últimos dez anos foram de forte expansão do software livre, tanto em termos de práticas e discursos em favor das licenças livres de software e de uma "cultura do compartilhamento" como no sentido de ter se tornado uma realidade dominante no mercado de informática. $\mathrm{O}$ incremento da velocidade na internet, a maior capacidade de processamento dos computadores e popularização dos dispositivos móveis de acesso à rede contribuíram decisivamente para uma mudança no modelo de negócios do mercado de informática, que progressivamente vem sendo dominado pela comercialização de serviços agregados em lugar do licenciamento de programas instalados nos computadores pessoais. Na implantação dessa infraestrutura, os softwares livres têm particular relevância, formando a base em que funcionam esses sistemas. ${ }^{16}$

Como fenômeno econômico e de produção descentralizada, o software livre desde logo atraiu a atenção da comunidade científica. Mais recentemente, surgiram estudos sobre a dinâmica política e cultural do mesmo. Este trabalho foi construído nessa direção, investigar o software livre buscando ressaltar seus aspectos culturais, entendendo-os como força operativa nos embates e disputas políticas inerentes ao movimento.

16 A referência aqui é a o que tem sido chamado de "cloud computing". Ver Barcet (2009).

Horizontes Antropológicos, Porto Alegre, ano 20, n. 41, p. 173-200, jan./jun. 2014 
Dessa forma, procurei inicialmente descrever a principal divisão política do software livre, distinguindo dois grupos majoritários em âmbito internacional, os quais representam algumas das ambiguidades do movimento. Sob o chapéu genérico da palavra liberdade constituíram-se os grupos free e open, que em certos momentos colocam-se como aliados, mas em outros são adversários políticos. Tentei apontar algumas das aproximações e diferenças dos grupos, atentando para o papel da ideologia enquanto força atrativa ou repulsora de adeptos free e open. Enquanto o grupo free reforça argumentos que levam em conta fundamentos morais de uma troca social de códigos de computador - o que é e o que não é justo, ético, etc. - o grupo open fundamenta-se no que seria o método de produção de um software de melhor qualidade. A reboque dessa distinção colocam-se ainda outros fatores, como o maior distanciamento ou aproximação com as empresas e com o sistema econômico capitalista tradicional.

A partir dessa distinção, procurei entender como o software livre se insere no Brasil, em um contexto político e social distinto do estadunidense, onde o movimento software livre se origina. Coleman (2004) aponta o software livre nos Estados Unidos - tanto o grupo free como o open - como eivado de um "agnosticismo político" e formado a partir de tradições liberais que o significam como um tipo de luta pela "liberdade de expressão". No Brasil, porém, o software livre ganhou força inicial principalmente entre sindicalistas e militantes sociais, alguns ligados a partidos políticos, que o significaram com outros sentidos, sendo entendido como ferramenta de independência e autonomia nacional, justiça social, arma contra a globalização corporativa e o neoliberalismo, entre outras bandeiras da esquerda. Assim, o Brasil acabou constituindo um movimento software livre bastante ativo politicamente - ainda que pouco atuante na produção de códigos livres. No processo de constituição do software livre no Brasil o grupo free teve força particular, estabelecendo uma forte interação com movimentos sociais e com lideranças políticas à esquerda no espectro político e permitindo uma associação produtiva entre as ideias políticas desses grupos e a ideologia free.

Isso, porém, não significou o abandono da polarização entre free e open no Brasil. Ao contrário, ela parece ter se tornado ainda mais evidentes. O Fórum Internacional de Software Livre evidencia os conflitos a cada uma de suas edições anuais. Nessa disputa política que se dá sobre o sentido do movimento, free e open afirmam seus posicionamentos também em relação ao

Horizontes Antropológicos, Porto Alegre, ano 20, n. 41, p. 173-200, jan./jun. 2014 
cenário político tradicional, entre esquerda e direita. Acho importante ressaltar como os debates sobre o software livre não acontecem desconectados das ideias políticas que permeiam a sociedade em seu contexto histórico. Dessa forma, o open, ao posicionar-se diferencialmente ao grupo free, faz suas aproximações mais à direita, incorporando as visões neoliberais e traduzindo-as para as brigas internas do movimento. Assim, o grupo open tem defendido o caráter capitalista do software livre e se posicionado de maneira contrária a muitos dos esforços feitos pelo Estado na disseminação e promoção dos softwares livres. A popularização deveria ocorrer "naturalmente", de acordo com a percepção do mercado, que os adotaria por serem programas de melhor qualidade.

O embate entre free e open, contudo, não se encontra parado no tempo e essa divisão política e ideológica é ressignificada e reinterpretada continuamente. É preciso ressaltar o fortalecimento recente das empresas de tecnologia open, que se tornaram um peso-pesado no ambiente do movimento software livre. Elas têm constituído seu negócio a partir de software livre e, da mesma forma, incorporam, formulam e transformam a ideologia do software livre, em especial em contato com o grupo open. Valores como a transparência, a descentralização da produção, uma postura aparentemente não gananciosa, as hierarquias flexíveis, a abertura, entre outros, passam a fazer parte da imagem dessas próprias empresas.

Barbrook (1998) ao comentar o que chama de high-tech gift economy, argumenta apontando o surgimento de uma nova economia, um misto de trocas capitalistas e não capitalistas no ciberespaço. $\mathrm{O}$ mercado, ao financiar o software livre, por exemplo, estaria patrocinando o anarcocomunismo na rede, a existência de trocas para além do Estado e das corporações. Ele afirma que o "copyright é protegido e quebrado. Os capitalistas se beneficiam de um lado e perdem de outro" (Barbrook, 1998, tradução minha). Naquele texto, escrito originalmente em 1998, ele posiciona o neoliberalismo e o que ele chama de "ideologia da Califórnia" - a mistura, surgida no primeiro boom da internet, de tecnoutopias neoliberais dos anos 1990 com uma postura antiautoridade herdeira da contracultura dos anos 1960 - como defensores das regras de propriedade intelectual vigentes.

Uma década e meia depois, acredito haver uma nova configuração dessas posições. O ponto não é mais a defesa das regras rígidas de propriedade intelectual, ao contrário, é o incentivo ao fluxo, à troca, à criação coletiva. 
As novas empresas buscam no movimento software livre códigos para suas operações comerciais e, eventualmente, funcionários para integrarem seus quadros. Trata-se de uma nova síntese de um conflito entre free e open, que persiste.

A ideologia em torno de cada uma das correntes políticas serve, embora não de modo exclusivo, como fator de atração para a colaboração e uso de determinados softwares. O grupo open, por exemplo, ao procurar distanciar-se das ideias políticas associadas especialmente a Richard Stallman, trouxe para dentro do movimento outros setores não identificados com a perspectiva política até então propagada pela Free Software Foundation - empresas e desenvolvedores de software com ideias mais à direita. Ao fazê-lo, mudou o balanceamento de poder dentro do movimento, poder esse manifesto não somente pelo apoio público a determinadas visões, mas também pela colaboração arregimentada em determinados projetos de software. Isso porque o software livre, possivelmente de maneira única se comparado a outros movimentos sociais, não obtém sua força política apenas pelo apoio simbólico dos militantes às suas causas, mas também porque esses militantes muitas vezes produzem softwares, ou seja, constroem produtivamente condições materiais para que sua causa tenha mais força.

Esse é um aspecto importante e diferencial do software livre com relação ao outros movimentos. O software livre não é um movimento que apenas demanda políticas e/ou busca por uma nova ordem de relações sociais, ao contrário, ele busca, a partir de um sistema jurídico já constituído, usar a lógica desse mesmo sistema para construir alternativas. A força do movimento não está em suas demandas, mas em sua capacidade de arregimentar trabalho voltado à produção-popularização de softwares que usam as regras convencionais, de forma inteligente, para garantir certas práticas. É um movimento que produz softwares e esses softwares se tornam produtos distribuídos no mercado de informática e que ocupam posições antes ocupadas, ou que poderiam ser ocupadas, por softwares proprietários. Por isso é especialmente relevante a análise das correntes políticas e ideológicas do software livre, pois elas se fortalecem em suas ligações produtivas com certos projetos de software assim como servem a esses projetos como fatores de atração de trabalho voluntário.

A entrada mais forte das corporações open impacta o software livre enquanto movimento, pois traz a ele militantes/colaboradores de perfil diferenciado, mais interessados no software livre pelas perspectivas profissionais que 
lhes são oferecidas. O perfil da base do movimento está em transformação, agora abarcando jovens interessados em carreiras mais tradicionais nas grandes empresas, carreiras semelhantes às dos executivos tradicionais das empresas transnacionais. Essa transformação pode ser acompanhada, no contexto brasileiro, em eventos como o Fisl.

\section{Referências}

APGAUA, R. O Linux e a perspectiva da dádiva. Horizontes Antropológicos, Porto Alegre, ano 10, n. 21, p. 221-240, jan./jun. 2004. Disponível em: $\quad<\mathrm{http}: / /$ www.scielo.br/scielo.php?script=sci_arttext\&pid=S0104$71832004000100010 \& \operatorname{lng}=$ en\&nrm=iso $>$. Acesso em: 20 jan. 2010.

BARBROOK, R. The high-tech gift economy. First Monday, v. 3, n. 12, 7 Dec. 1998. Disponível em <http://firstmonday.org/ojs/index.php/fm/article/ view/631/552>. Acesso em: 28 out. 2006.

BARCET, N. The importance of free software in the cloud. The Var Guy, 13 Oct. 2009. Disponível em: <http://thevarguy.com/ubuntu/importance-freesoftware-cloud>. Acesso em: 17 nov. 2009.

BENSON, T. Brazil: free software's biggest and best friend. The New York Times, 29 mar 2005. Disponível em: <http://www.nytimes.com/2005/03/29/ technology/29computer.html?_r=0>. Acesso em: 24 out. 2006.

COLEMAN, E. G. The political agnositism of free software and the politics of contrast. Anthropology Quarterly, p. 297-302, Summer 2004. Disponível em: $<$ http://www.healthhacker.org/biella/colemanaq.pdf $>$. Acesso em: 28 out. 2004.

FESTA, P. Governments push opensource software. Cnet, 29 ago. 2001 Disponível em $<$ http://news.cnet.com/2100-1001-272299.html $>$. Acesso em: 24 out. 2006.

FREE SOFTWARE is software that gives you the user the freedom to share, study and modify it. We call this free software because the user is free. Free Software Foundation, 2004-. Disponível em: <http://www.fsf.org/about/whatis-free-software>. Acesso em: 20 ago. 2013 
GILBERTO GIL: "Yo impulso la ética hacker". Clarín.com, 29 maio 2006. Disponível em: <http://www.clarin.com/diario/2006/05/29/um/m-01204505. htm>. Acesso em: 24 out. 2006

GOVERNADOR do software livre. Revista do Linux, n. 5, maio 2000. Disponível em: <http://augustocampos.net/revista-do-linux/005/index.html . Acesso em: 20 ago. 2013.

JELASSI, T.; ENDERS, A. Case study 16 - Google. In: JELASSI, T; ENDERS, A. Strategies for e-business: creating value through electronic and mobile commerce : concepts and cases. Essex: Pearson Education, 2005. p. 424.

KAUFMAN, W. Crowd sourcing turns business on its head. NPR, 20 ago. 2008. Disponível em: <http://www.npr.org/templates/story/story. php?storyId=93495217>. Acesso em: 20 ago. 2013.

KELTY, C. Two bits: the cultural significance of free software. Durham: Duke University Press, 2008. Disponível em: <http://twobits.net/pub/KeltyTwoBits.pdf>. Acesso em: 20 ago. 2013.

KINGSTONE, S. Brazil adopts opensource software. BBC News, 2 jun 2005. Disponível em: <http://news.bbc.co.uk/1/hi/business/4602325.stm>. Acesso em 24 out. 2006.

MURILLO, L. F. R. Tecnologia, politica e cultura na comunidade brasileira de software livre e de código aberto. Dissertação (Mestrado em Antropologia Social)-Instituto de Filosofia e Ciências Humanas, Universidade Federal do Rio Grande do Sul, Porto Alegre, 2009.

RAYMOND, E. S. A catedral e o bazar. Versão traduzida para o português por Erik Kohler. 1997. Disponível em: <http://www.dominiopublico.gov.br/ pesquisa/DetalheObraForm.do?select_action $=\&$ co_obra $=8679>$. Acesso em: 20 ago. 2013.

RAYMOND, E. S. Goodbye, "free software"; hello, "open source”. 22 Nov. 1998. disponível em: <ftp://ftp.lab.unb.br/pub/computing/museum/esr/opensource.html>. Acesso em: 27 dez. 2004. 
SANCHEZ, W. O movimento de software livre e a produção colaborativa do conhecimento. Dissertação (Mestrado em Ciências Sociais)-Faculdade de Ciências Sociais, Pontifícia Universidade Católica de São Paulo, São Paulo, 2007.

SHAW, A. Insurgent expertise: the politics of free/livre and open source software in Brazil. Journal of Information Technology \& Politics, v. 8, n. 3, p. 253-272, 2011.

STULZER, R. Os primórdios do Conectiva Linux. ComCiência, 10 jun. 2004. Disponível em: <http://www.comciencia.br/200406/reportagens/18.shtml>. Acesso em: 20 ago. 2013.

TEZA, M. Como organizamos o I FISL. Associação Software Livre. Org, 14 set. 2004. Disponível em: <http://wiki.softwarelivre.org/Pessoas/ ComoOrganizamosOIForumInternacionalSoftwareLivre>. Acesso em: 15 nov. 2009.

WEBER, S. The success of open source. Cambridge: Harvard University Press, 2004.

WILLIAMS, S. Free as in freedom: Richard Stallman's crusade for free software. March 2002. Disponível em: <http://www.oreilly.com/openbook/ freedom/>. Acesso em: 28 out. 2006.

WOLF, E. Culture: panacea or problem? In: WOLF, E. Pathways of power: building an anthropology of modern world. Berkeley: University of California Press, 2001. p. 307-319. 